\title{
A PRÁTICA PSICANALÍTICA FRENTE AO SUJEITO CONTEMPORÂNEO: REFLEXÕES A PARTIR DA CLÍNICA-ESCOLA
}

\author{
Psychoanalytic Practice in front of the Contemporary Subject: Reflections from the \\ Clinical-School
}

\section{La Práctica Psicoanalítica ante el Sujeto Contemporáneo: Reflexiones a partir de la Clínica-Escuela}

\section{Pratique Psychanalytique face au Sujet Contemporain : Réflexions à partir de la Clínique-École}

10.5020/23590777.rs.v20iEsp2.e8985

\author{
Victoria Ayelén Gómez 9 \\ Doutoranda em Psicologia Clínica e Cultura PPGPsiCC - UnB. Mestre em Psicologia Social, do Trabalho e das Organizações pela UnB. Psicóloga pela \\ Universidade Nacional de Córdoba (Argentina).
}

\section{Daniela Scheinkman Chatelard 9}

Professora associada no Programa da Pós-Graduação em Psicologia Clínica e Cultura - PCL do Instituto de Psicologia na Universidade de Brasília. Pósdoutorado na Universidade de Tel-Aviv - Departamento de Psicologia- Faculdade de Ciências Sociais (2020).

\section{Resumo}

Este trabalho debate acerca das contribuições da prática psicanalítica frente ao sujeito contemporâneo e das modalidades de expressão do sofrimento que nem sempre se apresentam sob a forma de sintomas ou são acompanhados de uma demanda de tratamento. Debate, ainda, o campo de atuação do psicanalista em instituições, tomando como referência a clínica do trabalho com adultos em uma clínica-escola. A análise foi desenvolvida a partir de uma experiência clínica de atendimento. Os pressupostos teórico-clínicos da experiência foram os da psicanálise e os da psicodinâmica do trabalho. A reflexão a respeito das diferentes práticas que utilizam a psicanálise como base, dentro do contexto da clínicaescola nas universidades, expõe novas formas de o sujeito contemporâneo se posicionar frente ao seu sintoma. Sugere-se uma função colaboradora de novas dinâmicas de atendimento. A proposta inclui pensar espaços de pesquisaintervençãocriação de dispositivos psicanalíticos de escuta inovadora. Concluímos pela importância da intervenção psicanalítica em instituições e ressaltamos a importância da transmissão do manejo clínico de base psicanalítica em instituições de ensino.

Palavras-chave: psicanálise; clínica-escola; sujeito contemporâneo.

\section{Abstract}

This paper discusses the contributions of psychoanalytic practice to the contemporary subject and the modalities of expression of suffering that do not always present themselves in the form of symptoms or are accompanied by a demand for treatment. It also discusses the field of activity of the psychoanalyst in institutions, taking as a reference the work clinic with adults in a school clinic. The analysis was developed from a clinical experience of care. The theoretical-clinical assumptions of the experience were those of psychoanalysis and psychodynamics of work. The reflection on the different practices that use psychoanalysis as a basis, within the context of the school clinic in universities, exposes new ways for the contemporary subject to position himself about his symptom. A collaborative role in new service dynamics is suggested. The proposal includes thinking about research spaces intervention creation of innovative listening psychoanalytic devices. We conclude the importance of psychoanalytic intervention in institutions and emphasize the importance of the transmission of clinical management based on psychoanalysis in educational institutions. 
Keywords: psychoanalysis; school clinic; contemporary subject.

\section{Resumen}

Este trabajo debate acerca de las contribuciones de la práctica psicoanalítica ante el sujeto contemporáneo y de las modalidades de expresión del sufrimiento que no siempre se presenta bajo la forma de síntomas o son acompañados de una demanda de tratamiento. Debate, aún, el campo de actuación del psicoanalista en instituciones, tomando como referencia la clínica del trabajo con adultos en una clínica-escuela. El análisis fue desarrollado a partir de una experiencia clínica de atendimiento. Las hipótesis teórico-clínicas de la experiencia fueron los del psicoanálisis y los de la psicodinámica del trabajo. La reflexión a respeto de las diferentes prácticas que utilizan el psicoanálisis como base, dentro del contexto de la clínica-escuela en las universidades, expone nuevas formas del sujeto contemporáneo tomar posición ante su síntoma. Se sugiere una función colaboradora de nuevas dinámicas de atendimiento. La propuesta incluye pensar espacios de investigaciónintervención-creación de dispositivos psicoanalíticos de escucha innovadora. Concluimos por la importancia de la intervención psicoanalitica en instituciones y enfocamos la importancia de la transmisión de la gestión clínica de base psicoanalítica en instituciones de enseñanza.

Palabras clave: psicoanálisis; clínica-escuela; sujeto contemporáneo.

\section{Résumé}

Cet article aborde les apports de la pratique psychanalytique face au sujet contemporain et des modes d'expression de la souffrance qui ne se présentent pas toujours sous forme de symptômes ou s'accompagnent d'une demande de traitement. Il aborde, également, le champ d'action du psychanalyste en institution, en prenant comme référence la clinique de travail avec des adultes dans une clinique-école. L'analyse a été développée à partir d'une expérience clinique de soins. Les hypothèses théorie-cliniques de l'expérience étaient celles de la psychanalyse et celles de la psychodynamique du travail. La réflexion sur les différentes pratiques qui utilisent la psychanalyse comme base, dans le cadre de la clinique-école dan les universités, expose de nouvelles manières pour le sujet contemporain de se positionner par rapport à son symptôme. Un rôle collaboratif des nouvelles dynamique des services est suggéré. La proposition comprend une réflexion sur les espaces de recherche-intervention-création de dispositifs psychanalytiques pour une écoute innovante. Nous concluons par l'importance de l'intervention psychanalytique chez les institution et nous soulignons l'importance de la transmission de la prise en charge clinique basée sur la psychanalyse dans les établissements d'enseignement.

Mots-clés : psychanalyse ; clinique scolaire ; sujet contemporain.

O artigo se propõe a refletir sobre as contribuições da psicanálise para a escuta do sofrimento do sujeito contemporâneo e as modalidades de expressão desse sofrer que nem sempre se apresentam sob a forma de sintomas ou são acompanhados de uma demanda de tratamento convencional. Um exemplo desse tipo de manifestação é o sofrimento relacionado ao trabalho. Atualmente, vem se desenvolvendo uma escuta inovadora (Gómez, 2017; Gómez, Mendes, Chatelard, \& Carvalho, 2016) denominada clínica do trabalho, com base na psicodinâmica do trabalho (PdT), que propõe uma leitura que aborda o sofrimento do trabalhador com base na lógica da singularidade de cada sujeito, considerando os significantes que marcam a história de cada trabalhador, sem, no entanto, negligenciar os determinantes e condicionantes sociais da produção desses sintomas na organização do trabalho.

Essa escuta utiliza uma intervenção de base psicanalítica, mas altera, na práxis, a técnica. A PdT é uma abordagem francesa criada por Christophe Dejours, influenciada pelas áreas da ergonomia, sociologia, filosofia e psicanálise. Trata-se de uma disciplina clínica, teórica e metodológica que trata das dinâmicas entre prazersofrimento, defesas e mobilização subjetiva (Dejours, 2011), sendo o acesso a esses processos permitido pela palavra. Nessa visão, a palavra expressa permite o conhecimento do que faz sofrer, ao mesmo tempo em que possibilita a ressignificação do prazer e do sofrimento no trabalho. A clínica do trabalho, desenvolvida a partir da PdT, é o espaço da fala e da escuta do sofrimento originado pela organização do trabalho (Mendes \& Araújo, 2012).

A clínica do trabalho propicia aos trabalhadores a criação de estratégias eficazes para afrontarem situações que provocam sofrimento. Privilegia a fala não só por proporcionar um espaço de escuta, mas também por promover o exercício de falar e de escutar, buscando pôr a palavra em ação (Mendes \& Araújo, 2012).

Segundo Rosa (2004), não se trata apenas de uma transposição de um modelo de tratamento para outros contextos ou para as problemáticas do sujeito contemporâneo. Existem limites do tratamento psicanalítico que nos incitam a propor novas formas intervenção, como no caso do sofrimento relacionado ao trabalho. Nesse sentido, se trata de repensar os limites do modelo de 
tratamento como conduzido nos consultórios, os limites da psicanálise como teoria, método, prática e ética para a condução das diversas modalidades de sofrimento. Desse modo, surge a ideia de discorrer a respeito das estratégias de intervenção frente às atuais manifestações sintomáticas, assim como as modalidades de sua extensão na prática psicanalítica extramuros.

Neste texto, interessa-nos a reflexão a respeito das práticas que utilizam a psicanálise como base, dentro do contexto da clínicaescola nas universidades. A psicanálise é uma teoria que, ao longo do tempo, se construiu a partir da experiência clínica daqueles que a estudam. A partir disso, a teoria, na atualidade, vem se propondo a ser utilizada em diversos espaços, sendo a clínicaescola o local por excelência para se iniciar a prática (Santos, Dauer, \& Martins, 2017). Dessa forma, a ideia é retomar, a partir da práxis em uma clínicaescola, as novas modalidades do sujeito contemporâneo se posicionar a partir do relato de um sofrimento em relação ao trabalho.

A psicanálise se mostra presente nas universidades brasileiras, em diferentes departamentos, em cursos de graduação e de pós-graduação (Aires, 2013) e, a partir disso, nos propomos a interrogar e a saber em que medida uma orientação pautada na psicanálise pode auxiliar na condução do serviço de acompanhamento e triagem para atendimento psicológico, contribuindo para o desenvolvimento de um estilo de escuta inovadora. Isso ocorre porque o sujeito, atualmente, sofre e orienta seu sofrer a partir de práxis novas e diferentes da psicanálise convencional.

$\mathrm{O}$ artigo se propõe, assim, a refletir sobre as contribuições da psicanálise para a escuta do sofrimento do sujeito contemporâneo a partir de uma escuta inovadora (Gómez, 2017; Gómez et al., 2016), denominada clínica do trabalho, com base na psicodinâmica do trabalho (PdT). Para alcançar o objetivo proposto, desenvolveram-se três eixos de análise, a saber: I - Clínicaescola e psicanálise; II - Experiência em uma clínica-escola: um estudo de caso; e III - Clínica do trabalho e condução clínica.

A investigação do tema deu-se a partir de diversos estudos atualmente conduzidos em laboratórios de pesquisa de uma universidade pública do CentroOeste do Brasil. Assim, mesmo esses estudos levantaram debates em um laboratório de psicanálise, subjetivação e cultura, do qual as autoras fazem parte.

\section{Clínica-Escola e Psicanálise}

A clínicaescola é uma formação pela prática em um lugar onde se ensina e se propicia um espaço de supervisão, discussão e construção do caso clínico. Trata-se de propiciar condições ao aluno para aprender com a vivência (Marcos, 2011). Igualmente, é o espaço no qual universidade e comunidade encontram um ponto de intersecção. Nesse espaço, o contato inicial com os pacientes ocorre na avaliação, na qual ocorrerá a escuta clínica e as triagens.

Seguindo a lógica de Aires (2013), a relação psicanálise-universidade deve ser pensada a partir de algumas afirmações: I - a universidade não foi o lugar de nascimento da psicanálise; II - a psicanálise prescinde da universidade; III - uma instituição de psicanálise pode vir a sustentar o lugar de formação de novos analistas, sem limitar a formação em psicanálise à sua apropriação teórica; III - a psicanálise também se ensina nas universidades, permitindo tornar público o conhecimento psicanalítico, bem como divulgar seus pressupostos; IV - a presença da psicanálise nas universidades não se restringe ao ensino, já que a psicanálise esteve presente desde a fundação das clínicas-escolas dos cursos de psicologia em universidades brasileiras a partir de atividades clínicas: atendimento, supervisão e discussão de casos; e V - na década de 1980, a psicanálise foi acolhida nos cursos de pós-graduação de diversas universidades brasileiras.

Para Freud (1919/1996b), as universidades só teriam a ganhar com a inclusão da psicanálise e, ainda não habilitando os estudantes de medicina a serem psicanalistas - sendo necessária uma formação adicional -, poderiam aprender algo sobre a psicanálise.

Atualmente, o ensino da psicanálise nas universidades não se dá mais pela via da medicina, como até meados do século XX, e sim por meio dos cursos de psicologia. Pensar a inclusão da psicanálise nos cursos de graduação de psicologia traz uma preocupação, com a qual Freud (1919/1996b) esteve atento, colocando o seguinte questionamento: como incorporar a psicanálise à estrutura educacional regular? (Silva, Silveira, Costa, \& Naue, 2018). Nesse sentido, Freud reconhece a importância dessa via de ensino, porém com os devidos cuidados, pois tem como guia o fato de a universidade não ser o lugar de formação de analistas.

Diversas modalidades clínicas têm utilizado a teoria psicanalítica e dispositivos vindos da psicanálise com o intuito de atender demandas da comunidade e dos sujeitos que não se enquadram na análise clássica. A inter-relação dessas demandas pode ser ilustrada a partir dos limites da prática psicanalítica frente ao sujeito contemporâneo e das modalidades de expressão do sofrimento, que nem sempre se apresentam sob a forma de sintomas ou são acompanhadas de uma demanda de tratamento. Nessas modalidades, o sofrimento relacionado ao trabalho se apresenta como um exemplo para utilizar a teoria psicanalítica.

A prática psicanalítica é útil no sentido de elucidar o discurso e as práticas sociais, a fim de problematizar os modos como os discursos afetam a subjetividade, e de escutar o sujeito, esclarecendo os modos pelos quais ele é afetado. Dessa 
forma, a psicanálise dispõe de elementos para essa prática (Rosa, 2004) e, então, consegue dialogar com o laço social que permeia o sofrimento do sujeito relacionado ao trabalho.

Neste texto, interessa-nos, mais do que entrar nos detalhes da clínica do trabalho, a reflexão a respeito das diferentes práticas que utilizam a psicanálise como base no contexto da clínica-escola nas universidades. Assim, questões culturais e diversas especificidades se encontram na atuação da clínica psicanalítica, como no contexto da clínicaescola e da clínica do trabalho. Nesse sentido, Birman (1994) coloca que a experiência psicanalítica aprova muitas possibilidades, desde que nessas variedades sejam reconhecidas as condições epistemológicas e éticas para a construção do espaço analítico, isto é, uma experiência centrada na fala e na escuta e regulada pelo impacto da transferência.

O sujeito busca o serviço porque sofre e quer uma resposta para o seu sofrimento. A clínica, no entanto, coloca-nos diante da impossibilidade dessa resposta. "Há um intervalo entre o pedido do paciente e a nossa resposta, não para superá-lo, mas para apreendê-lo em sua existência constante, tal é o saber em jogo na clínica" (Marcos, 2011).

A experiência do estágio nas clínicas-escolas proporciona aos alunos o aprendizado através da prática e das supervisões com o professor, sendo um de seus desafios o diálogo - possível - entre a psicanálise e aquilo que é norma da instituição. Nesse debate, tornam-se um desafio as questões apontadas por Santos et al. (2017), a saber: o tempo, a transferência e o pagamento.

A experiência em uma clínica-escola torna-se válida para poder analisar essas questões atreladas ao sujeito contemporâneo, que orienta sua fala a um sofrimento relacionado ao trabalho e às novas práticas do mundo do trabalho, trazendo à tona o que é esse novo posicionamento que foge ao que seria uma clínica psicanalítica no divã.

\section{A Experiência em uma Clínica-Escola}

A experiência relatada é uma pesquisa de mestrado realizada em uma universidade na Região CentroOeste. Nesse espaço universitário, começaram a surgir demandas de atendimentos de sujeitos que relatavam sofrimento. Tais demandas se apresentaram importantes em função da urgência de acolher o sofrimento relacionado ao trabalho e das dificuldades de acesso a atendimentos (e pesquisas) nos diversos ambientes de trabalho.

Dentre as demandas espontâneas de atendimento individual, surgiu a de uma trabalhadora do setor bancário, que relatava sofrimento relacionado ao trabalho. Na triagem, identificou-se que o sofrimento estava relacionado a mudanças na organização do trabalho bancário. A experiência clínica incluiu 18 sessões, entre os anos de 2015 e 2016, incluindo um encontro destinado ao acolhimento inicial (triagem), com o objetivo de identificar a demanda e examinar se estava alinhada ao escopo da prática. Sessões semanais de duração média de 50 minutos foram realizadas durante sete meses em sala destinada ao atendimento psicológico individual da clínica-escola. Após cada sessão, era realizada a supervisão do caso com a psicóloga coordenadora do projeto.

O primeiro encontro, chamado de triagem, teve duração de 30 minutos e foi realizado para verificar se a demanda estava alinhada ao escopo do projeto. A triagem objetivou coletar os dados de identificação, isto é: nome completo, data de nascimento, estado civil, idade, escolaridade, profissão, ocupação atual, tempo de serviço no cargo atual, afastamento ou não do trabalho, em acompanhamento psicológico e/ou psiquiátrico, uso de medicação controlada, se havia tido encaminhamento, e a queixa relativa à procura do atendimento. Depois da coleta dos dados de identificação, foi indagado à paciente: o que a trouxe até a clínica do trabalho? A partir desse primeiro encontro, orientou-se a condução clínica.

Os outros encontros já foram chamados propriamente de sessões e tiveram duração de 50 minutos, cumpridos rigorosamente, assim como a assiduidade aos encontros marcados. As sessões geralmente começavam com a frase: "te escuto". Essa abertura de sessão apresentou-se como a mais indicada em função de permitir que a trabalhadora organizasse e estruturasse suas ideias. Algumas sessões começaram com perguntas diretas em função do que foi trabalhado na supervisão. Procurou-se que todas as perguntas e pontuações nas sessões fossem realizadas com significantes e palavras que a participante usava.

Os procedimentos incluíram: encontros semanais, para favorecer o estabelecimento de vínculos e da transferência; número de sessões entre 10 e 18; supervisão das sessões e do caso; e estar atento a reconhecer o momento de finalizar o atendimento.

A partir da triagem da trabalhadora no decorrer da pesquisa, e também ao final dos atendimentos, definiu-se que a psicodinâmica do trabalho poderia ser complementada com a psicanálise e, de forma mais específica, com a noção de desamparo, elaborada por essa abordagem, para a compreensão do seu sofrimento. A escolha de abordar e complementar o sofrimento no trabalho, a partir da noção de desamparo da psicanálise, foi amplamente discutida em supervisão coletiva, a qual apontou a relação entre a organização do trabalho e o lugar que essa organização ocupava no sofrimento da trabalhadora. $\mathrm{O}$ trabalho tinha sido abraçado para preencher um vazio que se relacionava com o desamparo e o medo da perda. Esse lugar foi considerado impulsionado pela organização do trabalho bancário, mas, ao mesmo tempo, se articulava com o infantil da trabalhadora.

A condição de desamparo (hilflosigkeit) do homem refere-se à precariedade física e psíquica que fundamenta sua própria existência. De uma perspectiva físico-biológica, tem-se a prematuridade do humano quando do seu nascimento (desadaptação, sobrevivência e fragilidade do corpo). Do ponto de vista psíquico, tem-se um aparelho que não é capaz de 
manejar e dominar o aumento da tensão. Essa noção indica uma posição que se caracteriza pela incapacidade do ser humano frente a si mesmo e ao mundo. Impõe um esforço de sobrevivência e faz com que se desenvolvam as primeiras relações com o mundo externo e a construção do psiquismo, a partir da dependência de outro e pelos primeiros vínculos afetivos.

Uma leitura social da condição de desamparo relaciona essa condição originária com as formas de laço social na sociedade, na organização do trabalho e no mundo do trabalho (Birman, 1999; Mendes, Takaki, \& Gama, 2016; Safatle, 2015). Os pressupostos incluem pensar formas de submissão inseridas no campo dos afetos (Andrade, 2015), assim como considerar que o sujeito se envolve no discurso de sucesso, que remete à onipotência e que tampona o desamparo do vazio de trabalhar (Mendes et al., 2016).

Dessa forma, a psicodinâmica do trabalho e o conceito de desamparo ofereceram os alicerces para se relacionar, no estudo, as formas de vínculo entre organização do trabalhosofrimentosujeito. A proposta do estudo incluiu o referencial da psicodinâmica do trabalho e o referencial psicanalítico freudiano (e, em alguns momentos, lacaniano), como duas vertentes que colaboraram na escuta do sofrimento no trabalho, investigando-se, assim, os modos de subjetivação que se inscrevem no sujeito trabalhador.

A pesquisa enquadrou-se como estudo de caso clínico - método que descreve e interpreta o material clínico relativo à própria singularidade daqueles indivíduos que sofrem e demandam intervenção dos profissionais da área da saúde (Cunha, Palladino, \& Silva, 2015). O estudo de caso clínico expressa a própria singularidade do sujeito que sofre e a fala que ele dirige a um clínico (Franke \& Silva, 2012). Define-se como o relato de uma experiência singular, escrita por um clínico para atestar seu encontro com um paciente e apontar um avanço teórico (Franke \& Silva, 2012; Nasio, 2001).

Os resultados do caso clínico realizado em uma clínicaescola produzem conhecimento aprofundado de um objeto particular, e cumprem uma função de relevância: o trânsito entre a clínica e a pesquisa (Cunha et al., 2015). Assim, não se pretende uma verificação direta dos resultados, mas busca-se explicar e apontar para um sentido do(s) processo(s) estudado(s). Segundo Cunha et al. (2015), ao utilizar o estudo de caso clínico, o clínico-pesquisador assume que não se propõe a provar, mas sim a investigar, ilustrar e sugerir, orientando-se por parâmetros teóricos rigorosos que lhe permitam reformular proposições analíticas e não estatísticas.

Depois de realizado, o caso clínico em uma clínica-escola geralmente serve como parâmetro para discussão de uma teoria subjacente a uma técnica utilizada na condução dessa experiência (Moura \& Nikos, 2000). O caso clínico não se restringe a uma sistematização de dados restrita ao domínio do conteúdo ou discurso, mas, sim, ao domínio do sentido (Franke \& Silva, 2012).

A experiência apresentou, também, características que condizem com a chamada "construção do caso" (Moura \& Nikos, 2000), que traz implicitamente uma hipótese metapsicológica, a qual contempla elementos e conceitos da psicanálise e alude a uma produção que denota a experiência do pesquisador em sua investigação. Além disso, indica que o curso do processo (e sua comunicação pública como relato de pesquisa) não segue uma ordem cronológica, mas uma ordem lógica dos fenômenos abordados. Assim, o que interessa é a memória lógica que se inscreve no sujeito.

Segundo Franke e Silva (2012), a "construção do caso" exige a interlocução entre o clínico e uma alteridade supervisora, isto é, uma instância de supervisão que cumpre a função de alteridade na construção do caso. Uma experiência clínica dentro dos parâmetros propostos, com características de "construção do caso", fica sempre exposta a sugestões no terreno da metapsicologia. Assim, o clínico-pesquisador escreve, pois, o estudo de caso clínico colocando o texto como referência para outras pesquisas e para a gestão de novos problemas de pesquisa, assim como para novas construções.

São três as funções de um caso dentro da clínica-escola: didática, metafórica e heurística (Nasio, 2001). Função didática: o caráter cênico e figurado ajuda na transmissão da teoria de maneira ativa e concreta. Mostra os conceitos e, ao mostrá-los, transforma o leitor num ator que, pela encenação improvisada de um papel, inicia-se na prática e assimila a teoria. A escrita facilita o acesso ao pensamento abstrato, colocando os conceitos em imagens. Função metafórica: o sentido inicial de uma ideia pode tornar-se, pouco a pouco, o próprio sentido de seu exemplo, a tal ponto que basta a simples menção do nome próprio do caso (Dora, Anna, Hans) para fazer com que brote a significação conceitual. Coloca-se a possibilidade de que "o caso" seja estudado e retomado a ponto de adquirir um valor emblemático. Função heurística: pode suceder que o caso ultrapasse seu papel de ilustração e de metáfora emblemática, tornando-se, em si mesmo, gerador de conceitos.

\section{Clínica do Trabalho e Condução Clínica}

A sensação de desamparo foi relatada no primeiro encontro (triagem), mas essa leitura da questão foi desenvolvida no decorrer das sessões. A interpretação e construção dessa noção foram realizadas simultaneamente aos atendimentos em curso e finalizadas com o término dos atendimentos. Nessa perspectiva, escutar a palavra do outro impõe ao clínico a tarefa de produzir palavras que vão ao encontro dessa demanda de ajuda. Freud entrega a palavra ao próprio paciente para que ele fale sobre si mesmo e não sobre o que a nosografia disse sobre ele (Macedo \& Falcão 2005). 
A triagem trouxe os primeiros elementos: Laura (nome fictício) relatou, no primeiro encontro, um ponto de esgotamento e pontuou explicitamente que vinha sentindo isso desde 2004. Essa nomeação marcou um ponto central no tempo, uma sinalização que apontava para uma questão específica: a reorganização e reestruturação da organização do trabalho que a trabalhadora vivenciou.

No mesmo encontro, a trabalhadora pontuou que, dessa maneira, ela estava numa situação muito "insegura" e "instável”, e que isso era "curioso", porque ela era servidora pública justamente por causa da segurança do emprego. Somado a isso, trazia sentimentos de sofrimento, irritabilidade, sensação de cansaço extremo e pontuou que "o trabalho estava insuportável". Já na triagem, relatou que tinha a possiblidade de se aposentar no ano seguinte, mas que não conseguia pensar nisso.

Após o primeiro encontro de supervisão, foram realizadas leituras que suscitaram diversos questionamentos: se o trabalho se mostrava insuportável para Laura, por que ela não conseguia pensar na aposentadoria? Assinalou-se um momento específico, então: como pensar o impacto dessa mudança nas vivências de sofrimento? Por que ela não conseguia "sair desse negócio"? O que significava "sair" para ela?

O primeiro encontro foi a peçachave para isso se constituir um enigma a ser desvendado. Laura demandava respostas: "Porque não peço minhas contas e me aposento?"; "Quero entender o que acontece dentro de mim que fico presa". Essa fala apontou para processos encobertos/recalcados que entraram em cena e que ela queria explorar.

Mostrava-se evidente que a mudança na organização do trabalho era o principal motivo do seu sofrimento e que, a exemplo da falta de reconhecimento, tinha gerado consequências psíquicas. No entanto parecia que algo do sofrimento se inscrevia de forma singular.

No decorrer das sessões, Laura falava de "abandono", "segurança" e do medo de sair "lá fora", o que indicava algumas equivalências: banco $\sim$ segurança $\sim$ proteção $\sim$ amparo; lá fora $\sim$ insegurança $\sim$ desproteção $\sim$ desamparo.

A bancária se encontrava "cedida" e "exilada", mas com resquícios de "segurança" e "amparo", visto que ainda era funcionária do banco: "será que estou fantasiando demais? Que o mundo lá fora é difícil demais? É esse sofrimento mesmo que sobra (...), sensação de abandono".

Quando se tratava o tema da aposentadoria nas sessões, a trabalhadora expressava ser uma decisão difícil porque envolvia questões financeiras, perda salarial e mudança de vários fatores "estruturantes". Não queria mais estar naquele trabalho, mas eram 30 anos de carreira que não conseguia soltar. Chorava e falava que ficava paralisada só de pensar nisso.

Nas sessões, emergiam cada vez mais elementos que permitiam pensar a figura do banco como associada à proteção e amparo. A interpretação do desamparo liga o medo ao sentimento de vulnerabilidade, oriundo do fato de se estar dependendo de outro. Trata-se de um legado que nos posiciona numa demanda de amor ao outro para que seja possível a sobrevivência, que é material no início, mas se torna psíquica. É um sentimento que circula no sujeito e é reativado nos momentos de encontro com o novo ou o desconhecido; sentimento atravessado pelo medo.

Assim, Laura se encontrava nesse raciocínio, captado pela forma de gestão do trabalho bancário, que estimula e gerencia o medo. Obteve-se, assim, a adesão da trabalhadora, que se tornou a filha boazinha, a qual, por medo da perda de amor ( segurança), se submetia às exigências ("servidão voluntária, não é isso?") do sistema. De igual forma, a noção de desamparo é compreendida quando se analisa a organização do trabalho que promove as ideias do trabalhar de forma perfeita, numa lógica que nega os erros, fracassos e falhas; logo, que nega o desamparo estrutural com o qual cada sujeito deve lidar.

Tratando-se de uma pesquisa clínica, o caso acompanhou uma mudança subjetiva da trabalhadora. Os atendimentos permitiram a Laura um processo de aceitação dos próprios limites, dos erros e dos sofrimentos como parte do trabalhar, dos seus desejos e da não "certeza absoluta das possibilidades e escolhas".

A clínica do trabalho almeja não atender à demanda do sujeito e colocá-lo frente ao enigma do seu desejo. Por conseguinte, o clínico permitiria o surgimento do desejo como questão, apontando para o outro lugar em que ele se situava: o desejo do outro (Silveira, Feitosa, \& Palácio, 2014). É assim que o sujeito começa a perceber a sua implicação naquilo de que vinha se queixar e o sintoma adquire o estatuto de uma pergunta: será que foi por isso que eu adoeci? (Silveira et al., 2014). Ela almeja colocar em crise o que é tido por "normal" quando a normalidade é um sintoma de violência e opressão (Périlleux \& Mendes, 2015) e, nessa perspectiva, impõe-se o desafio de se aproveitar a crise como ocasião de abertura das controvérsias sobre os valores do trabalho. Trata-se de restaurar a voz de sujeitos críticos e de emergir a possibilidade de uma palavra.

O dispositivo clínico é operado pela palavra como um revelador, e uma questão fundamental da clínica é constituir o mal-estar em sintoma, de forma a proceder de tal maneira que o sintoma possa se dizer (Périlleux \& Mendes, 2015). Insistese na ideia de que a repetição de um sintoma tem uma função: sustentar-nos na existência, fazer sentirmo-nos integrados (Périlleux \& Mendes, 2015). É na clínica do trabalho que se abre o espaço para se nomear esses sintomas, inscrevê-los na ordem da palavra e, então, elaborá-los.

Périlleux e Mendes (2015) apontam que, na clínica do trabalho, é fundamental buscar confrontar a frustração da impotência e assumir sua condição de desamparo. Muitas vezes, a relação onipotência-impotência é acessada em função de uma perversa organização do trabalho, com falsas promessas de reconhecimento do trabalho e (ao mesmo tempo) desqualificação constante. 
As demandas que a organização do trabalho desenha são pautadas na ideologia da excelência, que não oferece espaço para as falhas do humano e produz subjetividades que se desestabilizam ante a impotência do confronto com o real.

\section{Considerações Finais}

O sintoma foi um enigma a ser decifrado. Transformar a queixa inicial em um enigma só foi possível pela instauração da transferência, a qual é conceituada por Freud (1996a) como reedições das fantasias infantis que vão se atualizar na pessoa do analista.

Realizou-se uma leitura que abordou a saúde da trabalhadora com base na lógica da singularidade, considerando os significantes que marcaram a história da trabalhadora, mas sem deixar de ponderar os determinantes e condicionantes sociais da produção desses sintomas manifestados na organização do trabalho. Consequentemente, a leitura política dos sintomas de Laura foi abordada como enigma a ser decifrado, em função de condicionantes sociais, históricos, contextuais e da organização do trabalho bancário, desdobrados num sujeito singular com uma história particular.

No decorrer do processo clínico, Laura começou a relacionar a frustação e incompetência que sentia no trabalho com "o sistema bancário". Começou a expressar que, com a clínica do trabalho, ela estava conseguindo perceber que não era incompetência sua. Assim, começou a elaborar que deveria estar fora desse "sistema", assumindo que tinha limites e cometia erros que não eram ponderados no trabalho.

Foi assim que Laura começou a perceber a sua implicação naquilo de que vinha se queixar. O sofrimento que ela sentia começou a adquirir estatuto de uma pergunta: "Será que foi por isso que eu adoeci?" (Silveira et al., 2014). Abriu-se o espaço para uma crise emergir, para ativar controvérsias quanto aos valores perseguidos na execução do trabalho e colocar em crise o que era tido por "normal" quando essa normalidade fazia referência a um contexto de violência e opressão (Périlleux \& Mendes, 2015). Aproveitou-se a crise e restaurou-se a voz da trabalhadora, dando-lhe a possibilidade da palavra.

A condução em clínica do trabalho implicou uma escuta qualificada sobre o sofrimento no trabalho - uma escuta que privilegiou a palavra. A escuta clínica do trabalho visou denunciar aspectos da organização do trabalho que se apresentaram como banais, colocando em tensão a ideia de onipotência que a gestão do trabalho pregava. A interpretação apontou que o pai representava o banco e vice-versa, numa condensação que incluía a lógica da segurança. A condensação abrangia essas duas figuras como fusionadas numa conexão que representava aspectos de proteção associados a elementos infantis. Movia-se numa lógica que indicava uma demanda de amor, ou seja, medo da perda do amor - amor equivalente ao amparo e segurança. Encontrou-se que a trabalhadora foi atravessada pelo medo, sentimento que foi captado pela forma de gestão do trabalho bancário que estimula e gerencia o medo, obtendo a adesão da trabalhadora.

Este trabalho, assim, discutiu as contribuições da prática psicanalítica frente ao sujeito contemporâneo e as modalidades de expressão do sofrimento, que nem sempre se apresentam sob a forma de sintomas ou são acompanhadas de uma demanda de tratamento convencional de análise. Defendeu o campo de atuação do psicanalista em instituições, tomando como referência a clínica do trabalho com adultos em uma clínicaescola.

A análise foi desenvolvida a partir de uma experiência clínica de atendimento em uma clínica-escola. Os pressupostos teóricoclínicos da experiência foram os da psicanálise e da psicodinâmica do trabalho. A reflexão a respeito das diferentes práticas que utilizam a psicanálise como base, dentro do contexto da clínicaescola nas universidades, expôs novas formas de o sujeito contemporâneo se posicionar frente ao seu sintoma, orientando sua fala para um sofrimento que se relaciona com o novo mundo do trabalho. Nessas discussões, sugeriu-se uma função colaboradora de novas dinâmicas de atendimento. A proposta incluiu pensar espaços de pesquisaintervençãocriação de dispositivos psicanalíticos de escuta inovadora.

Percebe-se que a psicanálise mostra-se presente nas universidades brasileiras em diferentes departamentos, em cursos de graduação e de pós-graduação (Aires, 2013). A partir disso, tentamos refletir e saber em que medida uma orientação pautada na psicanálise pode auxiliar na condução do serviço de acompanhamento e triagem para atendimento psicológico, contribuindo para o desenvolvimento de um estilo de escuta inovadora.

Percebe-se que questões culturais e diversas especificidades se encontram na atuação da clínica psicanalítica, como no contexto da clínicaescola e a clínica do trabalho. Nesse sentido, Birman (1994) coloca que a experiência psicanalítica aprova muitas possibilidades, desde que nessas variedades sejam reconhecidas as condições epistemológicas e éticas para a construção do espaço analítico, isto é, uma experiência centrada na fala, na escuta e regulada pelo impacto da transferência.

Assim, consideramos que a clínicaescola mostra-se um lugar fértil para trabalhar a elaboração de dispositivos inovadores, utilizando-se da psicanálise para atender demandas que fogem da análise pautada convencional, abordando as novas vicissitudes no sujeito contemporâneo. Dessa forma, admitem-se novas demandas espontâneas que colocam a clínicaescola no lugar de oferecer um atendimento que permite aos estudantes entrar em contato com uma prática clínica pautada nos dispositivos da psicanálise. 
O sujeito busca o serviço porque sofre e quer uma resposta para o seu sofrimento, e a clínica nos coloca diante da impossibilidade dessa resposta. "Há um intervalo entre o pedido do paciente e a nossa resposta, não para superá-lo, mas para apreendê-lo em sua existência constante, tal é o saber em jogo na clínica" (Marcos, 2011). A partir dessa busca, delineiam-se novas formas de intervir, uma escuta inovadora - como pode ser a psicanálise - e a escuta do sujeito que sofre em relação ao trabalho.

A análise foi desenvolvida a partir de uma experiência clínica centrada no atendimento de um sujeito, com base nos pressupostos teórico-clínicos da psicanálise e da psicodinâmica do trabalho, tendo sido privilegiada a falaescuta do sofrimento relacionado ao trabalho. A questão básica que norteou o trabalho consistiu em discutir acerca das contribuições da prática psicanalítica convencional frente ao sujeito contemporâneo e das modalidades de expressão do sofrimento, que nem sempre se apresenta sob a forma de sintomas ou é acompanhado de uma demanda de tratamento convencional.

A partir do exposto, sugere-se uma função colaboradora de novas dinâmicas de atendimento. A proposta inclui pensar espaços de pesquisaintervençãocriação de dispositivos psicanalíticos em diálogos com diferentes saberes. Concluímos pela importância da intervenção psicanalítica em instituições e ressaltamos a importância da transmissão do manejo clínico de base psicanalítica em instituições de ensino.

\section{Referências}

Aires, S. (2013). Imagens do analista na universidade. Trivium - Estudos Interdisciplinares, 5(1), 30-38.

Andrade, E. (2015). Circuito dos afetos: Corpos políticos, desamparo, fim do indivíduo. Perspectiva Filosófica, 42(1), 54-58.

Birman, J. (1994). Psicanálise, ciência e cultura. Rio de Janeiro: Jorge Zahar.

Birman, J. (1999). Mal-estar na atualidade: a psicanálise e as novas formas de subjetivação. Rio de Janeiro: Civilização Brasileira.

Cunha, M. C., Palladino, R. R. R., \& Silva, M. F. F. (2015). Estudo de caso clínico na pesquisa fonoaudiológica: Da cena clínica às formulações teóricas. Distúrbios Comun. 27(1), 192-195.

Dejours, C. (2011). Addendum: Da psicopatologia à psicodinâmica do trabalho. In Lancman, S., \& Sznelwar, L. I. (Orgs.), Christophe Dejours: Da psicopatologia à psicodinâmica do trabalho (pp. 47-104). Rio de Janeiro: Editora Fiocruz.

Franke, D., \& Silva, J. C. (2012). Da escuta à escrita: A construção do caso clínico em psicanálise. Psicanálise \& barroco em revista, 10(2), 42-61.

Freud, S. (1996a). A interpretação dos sonhos. In J. Strachey (Ed.), Edição Standard Brasileira das Obras Psicológicas Completas de Sigmund Freud (vol. 4 e 5). Rio de Janeiro: Imago.

Freud, S. (1996b). Sobre o ensino da psicanálise na universidade. In J. Strachey (Ed.), Edição Standard Brasileira das Obras Psicológicas Completas de Sigmund Freud (vol.17). Rio de Janeiro: Imago. (Originalmente publicado em 1919)

Gómez, V. A. (2017). Desamparo e sofrimento no trabalho bancário: Um estudo de caso em clínica do trabalho. (Dissertação de Mestrado). Link

Gómez, V. A., Mendes, A. M., Chatelard, D. S., \& Carvalho, I. S. (2016). A palavra como laço social na clínica psicodinâmica do trabalho. Contextos Clínicos, 9(2), 253-264. DOI: 10.4013/ctc.2016.92.10

Macedo, M. M. K., \& Falcão C. N. B. (2005). A escuta na psicanálise e a psicanálise da escuta. Psychê, 10(15), 65-76.

Marcos, C. M. (2011). Reflexões sobre a clínica-escola, a psicanálise e sua transmissão. Psicologia Clínica, 23(2), 205-220.

Mendes, A. M., \& Araújo, K. R. (2012). Clínica da psicodinâmica do trabalho: O sujeito em ação. Curitiba: Juruá.

Mendes, A. M., Takaki, K., \& Gama, L. P. (2016). Do sujeito invocado ao sujeito invocante: A violência no trabalho como 
recusa do desamparo. In B. Farah (Org.), assédio moral e organizacional: Novas modalidades do sofrimento psíquico nas empresas contemporâneas (pp. 151-160). Brasília: LTR80.

Moura, A., \& Nikos, I. (2000). Estudo de caso, construção do caso e ensaio metapsicológico: Da clínica psicanalítica à pesquisa psicanalítica. Pulsional Revista de Psicanálise, 13(140/141), 69-76.

Nasio, J. D. (2001). Que é um caso? In J. D. Nasio, Os grandes casos de psicose (pp.11-22). Rio de Janeiro: Jorge Zahar.

Périlleux, T., \& Mendes, A. M. (2015). O enigma dos sintomas: Proposição para uma escuta psicanalítica e política do sofrimento no trabalho. Revista Trivium Esudos Interdisciplinares, 1(1), 61-73.

Rosa, M. D. (2004). A psicanálise e as instituições: Um enlace ético-político. In: Colóquio do LEPSI IP/FE-USP, 5. Link

Safatle, V. (2015). O circuito dos afetos: Corpos políticos, desamparo e o fim do indivíduo. São Paulo: Cosac e Naify.

Santos, J. C. G., Dauer, E. T., \& Martins, K. P. H. (2017). Uma psicanálise possível: Entrelaçamentos de uma prática psicanalítica em uma clínica-escola no sertão central do Ceará. Revista Expressão Católica Saúde, 2(1), 73-76.

Silva, W. S. S., Silveira, L. R., Costa, G. M., \& Naue, L. A. V. (2018). Das possibilidades de trabalho com a psicanálise no contexto de uma clínica-escola. Estudos Interdisciplinares em Psicologia, 9(1), 143-156.

Silveira, L. C., Feitosa, R. M. M., \& Palácio, P. D. B. (2014). A escuta do sofrimento psíquico relacionado ao trabalho: Contribuições da psicanálise para o cuidado em saúde. Psicologia em Revista, 20(1), 19-33.

\section{Como citar:}

Gómez, V.A., \& Chatelard, D. S. (2020). A Prática Psicanalítica frente ao Sujeito Contemporâneo: Reflexões a partir da ClínicaEscola Revista Subjetividades, 20(Esp 2. O Contemporâneo à Luz da Psicanálise), e8985. http://doi.org/10.5020/23590777. rs.v20iEsp2.e8985

\section{Endereço para correspondência}

Victoria Ayelén Gómez

E-mail: victoria.ayelen.gomez@gmail.com

Daniela Scheinkman Chatelard

E-mail: dchatelard@gmail.com 